\title{
Level of Depression in Positive Patients for COVID-19 in the Puente Piedra District of North Lima, 2020
}

\author{
Rosa Perez-Siguas ${ }^{1}$, Eduardo Matta-Solis ${ }^{2}$, Hernan Matta-Solis ${ }^{3}$ \\ Anika Remuzgo-Artezano ${ }^{4}$, Lourdes Matta-Zamudio ${ }^{5}$, Melissa Yauri-Machaca ${ }^{6}$ \\ Research and Intellectual Creativity Direction, Universidad María Auxiliadora, Lima, Perú ${ }^{1,2,3,4}$ \\ Health Sciences, Instituto Peruano de Salud Familiar, Lima, Perú ${ }^{5}$ \\ Research and Technology Direction, Business on Making Tecnologies, Lima, Perú ${ }^{6}$
}

\begin{abstract}
Depression in the positive patient for COVID-19 is one of the emotional confrontations that must endure during isolation and quarantine, therefore, the objective of the research study is to determine the Level of Depression in positive patients for COVID-19 in the district of Puente Piedra in North Lima, 2020. This is a quantitative, non-experimental, descriptive and cross-sectional study, making a flow chart in relation to home care by the nursing professional in a population of 23 Positive patient for COVID-19 from the Puente Piedra district of North Lima, who answered a questionnaire with Sociodemographic data and the self-assessment scale for Zung's depression. In the results where we can observe, with respect to the level of depression in patients positive for COVID-19, where 14 patients represent $60.9 \%$ of the total are with a normal level of depression, 9 patients represent $39.1 \%$ of the total are slightly depressed. In conclusion, it is necessary to intervene in the psychological aspect according to the characteristics of each patient such as gender and age, in the future, it is recommended to carry out more research at the national level, as it will allow researchers to go into more detail about the mental health of the patient during and after the COVID-19 pandemic.
\end{abstract}

Keywords-Depression; coronavirus; patients; home care

\section{INTRODUCTION}

The coronavirus disease (COVID - 19) has had a great impact on the world population both in their mental and physical health, therefore, it is expected that COVID - 19 since it appeared in December 2019, was widely recognized as a traumatic event for patients who tested positive for this disease, because it imposes a threat not only due to concerns at the physical level [1], but also at the mental level of infected patients, since they experience fear, sadness, melancholy, insomnia, and helplessness, where all this affects the patient exposing them to serious health problems related to the disease [2].

In the positive patients for COVID-19, they have been considered vulnerable in the mental aspect, because this desease presents depressive symptoms that prevent them from advancing in their life, it has been expected that positive patients with depressive symptoms do not tend to communicate with others and do not seek support from their relatives, because their perception of dignity and shame have been barriers that prevent them from seeking help [3], also, in positive patients for COVID-19 who are at risk or who suffer depression during and after the disease outbreak as a result of isolation and quarantine, an increase in suicidal thinking and behavior could be considered in the short or long term [4].

Therefore, the mental health of the patient plays an important role during this crisis due to the COVID-19 pandemic [5] since they are predisposed to be vulnerable and lead to serious psychological consequences in the patient in relation to their person, environment and family.

In Hong Kong [6], it could be observed in 500 participants surveyed in the research work on depression during the COVID-19 pandemic, indicating that the prevalence rate for depression is considerable in the population, where $29 \%$ of people presented mild depression, $12.8 \%$ moderate depression, $6.2 \%$ moderately severe depression and $0.8 \%$ severe depression allowing to observe that depressive conditions affect the population during the COVID-19 pandemic.

In China [7], a study was conducted in 1593 participants in relation to the comparison between prevalence and factors associated with depression during the quarantine due to the COVID-19 pandemic in Southwest China in a population infected and not infected by the coronavirus, where the prevalence of depression in the infected population was $14.6 \%$, stating that $8.3 \%$ had mild depression, $5.2 \%$ had moderate depression and $1.1 \%$ had severe depression, due to this they showed a high prevalence of depression in the infected population than in the uninfected population.

In Spain [8], a virtual survey was conducted with 976 participants during the first phase of the COVID - 19 outbreak in northern Spain, mentioning depression during the first phase of the COVID - 19 outbreak in Basque men and women, where $78(8.6 \%)$ of the women presented mild depression, 16 (7.1\%) moderate depression, $20(2.3 \%)$ severe depression and $34(3.0 \%)$ extremely severe depression, in men $19(8.7 \%)$ had mild depression, $9(4.0 \%)$ moderate depression, 5 (2.9\%) severe depression and $3(1.7 \%)$ extremely severe depression, concluding that Basque men and women present evidence of depressive symptoms from the COVID-19 pandemic.

The objective of the research work is to determine the level of depression in positive patients for COVID-19 in the 
Puente Piedra district of North Lima, 2020. This study is important since it provides relevant and real data on mental vulnerability with respect to depression in COVID-19 positive patients treated at home by nursing professionals. In this research work, the survey will be used as a data collection instrument, the data to be entered will be given in a data matrix that will be designed in the statistical program IBM SPSS Statistics Base 25.0, its corresponding analysis was carried out, in which it will allow a better data processing for the realization of statistical tables and graphs so that they are later described and interpreted in results and discussions, respectively.

The following research work is structured as follows: In Section II, the development of the data collection processing of hospitalized patients will be presented and also the guidelines to be considered so that they are within the research work. In Section III, the results will show the level of depression in coronavirus positive patients according to the specified dimensions of the instrument in the measurement of the variable. In Section IV, we present the discussions of the research work and in Section $\mathrm{V}$ the conclusions.

\section{Methodology}

In this part, a flow chart will be developed based on protocols to be followed by the nurse's care towards the coronavirus positive patient at home, the type and design of the research work, also the population and sample that it will be carried out in the research work, the inclusion criteria in detail and finally the data collection technique and instrument that is the survey, where it was taken by the nurse in charge of caring for the patient with COVID - 19, see Fig. 1. In this flow chart the protocols to be followed in patient care will be described, it starts in two partitions:

First, the nursing protocols will be given on the care of the patient at home, this refers to the care performed by the nursing professional towards the patient, the care to be carried out will manifest itself in five processes:

- First, it is the use of biosafety equipment such as N95 mask, face shield, protective glasses, gloves, and overalls, this allows the safety of both the nursing professional to come into contact with the patient and the family and thus be able to carry out the corresponding care.

- Second, it is the disinfection process, such as hand hygiene with soap, water and alcohol gel.

- Third, it is the monitoring of the COVID-19 disease, this process the nursing professional will monitor the patient their vital functions such as oxygen saturation, respiratory rate, temperature, blood pressure and heart rate allowing to observe if there is any alteration that predisposes that the disease is still active.

- Fourth, it is the treatment of the COVID-19 disease, in this process the procedures will be carried out according to the severity of the disease in the patient, if the disease is mild or moderate in which it will be verified if the patient is in oral treatment or it is on oral treatment and injection therapy [20].

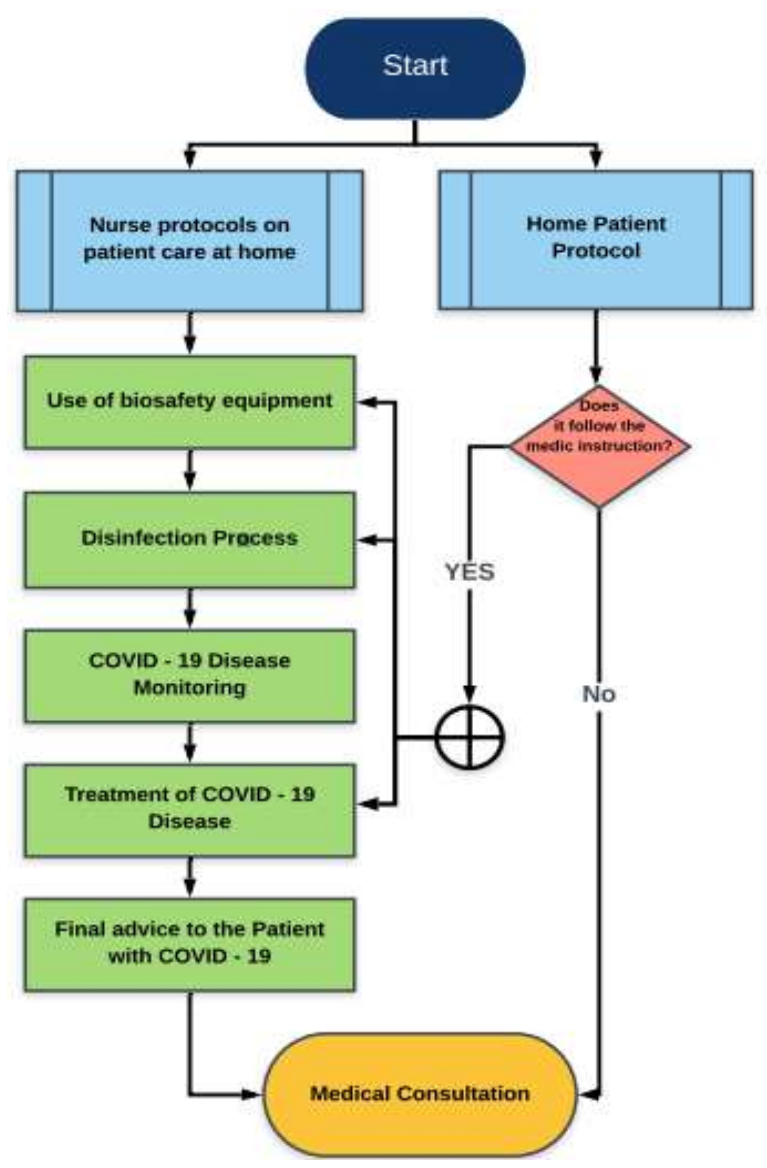

Fig. 1. Flowchart of the Nursing Professional on the Home Care Performed for the Patient with COVID-19.

- In fifth place, it is the final counseling to the patient with COVID-19, in this process the nursing professional will provide information to the patient about hand hygiene (the steps to follow and how to do them), healthy eating (foods rich in vitamins and minerals; and what foods are not).

Once all this is done, the patient will have their routine medical consultation, in which the physical examination will be performed, and also the laboratory examination to rule out if the disease is still active in the patient.

Second, the protocols to be followed by the patient at home will be given, but it will depend on a question with two answers, the question is, does patient follow all the steps? referring to the care that the doctor referred them, and the answers are, if they meet them or do not comply with them [21], the first response if it does, the patient will follow three processes:

- The first process is the use of biosafety equipment, where the patient must have the mask available, either simple or the N95, this will allow the patient through sneezing and the presence of cough, do not infect family members who live with them.

- Second process is the disinfection process, this process the patient should perform hand hygiene with soap and water, this will eliminate the bacteria present on the 
hand and not spread through the skin to family members.

- Third process is the treatment of the COVID-19 disease, in this process the patient must follow the indications prescribed by the doctor, but depending on the degree to which the mild or moderate disease is found, in which oral treatment or oral treatment and injection therapy.

After all these processes, they should go to routine medical consultations for controls, the second answer if they do not comply with the instruction of the doctor, the patient should go to a medical consultation to verify the degree of the disease, it is very important to take into account that when at the time of the general examination of the patient, if a decrease in oxygen saturation is observed, the doctor will indicate if they will transfer to the hospital where they are subscribed to a life security because they will need support oxygen and also will continue the treatment indicated.

\section{A. Research Type and Design}

The present study, due to its characteristics, way of collecting data and measuring the variables involved, has a quantitative approach. Regarding the methodological design, it is a non-experimental, descriptive, cross-sectional study [9].

\section{B. Population and Sample}

In the present study, the population is made up of 23 COVID-19 positive patients who are undergoing treatment at their home in North Lima in the Puente Piedra district of the Micaela Bastidas Association.

\section{Inclusion Criteria}

- COVID-19 positive patients in the Puente Piedra district, Micaela Bastidas Association - Zapallal.

- Patients who are undergoing COVID-19 treatment at home.

\section{Technique and Instrument}

The technique used is the survey, through the questionnaire or data collection instrument of the Zung Depression Self-Assessment Scale (SDS), which aims to measure depression in coronavirus-positive patients.

The Zung Depression Self-Assessment Scale (SDS) is selfadministered to assess how depressed a patient is, the scale consists of 20 items that indicate 4 most common characteristics of depression: the dominant effect, the physiological equivalents, other disturbances and psychomotor activities. There are 10 items elaborated in a positive way and 10 items in a negative way that are evaluated on a Likert-type scale where 1 "little time", 2 "some of the time", 3 "a good part of the time" and 4 "most of the time". The range of the scale goes from 20 to 80 [10], the higher the score, the more depression the patient presents.

\section{E. Place and Application of the Instrument}

The questionnaire carried out to measure the level of depression in positive patients for coronavirus, was carried out in North Lima, in the Puente Piedra district, of the Micaela Bastidas - Zapallal Association.
First, the necessary permits were made for this research work, coordinated with the family in charge of the patient to carry out the questionnaire, then the permission to the patient explaining about the questionnaire and why the research work is being carried out so that they have knowledge about of what is going to be done.

The questionnaire was carried out in the mornings with an approximate time of 15 minutes in each patient surveyed in the research work [19], reaching a conclusion with good satisfaction at the time of collecting the questionnaires that the patients supported for the research work.

It is important to emphasize the presence of the family in charge of the patient at the time of filling he questionnaire, because there is a possible adverse event from the disease in the patient and that the family member provides the treatment that it is receiving and thus avoid damages that can be considerable in the health of the patient. At the same time, the presence of the nursing professional is also important, since they will perform the care of the patient and also have knowledge about the necessary care of COVID-19 patients who are cared for at home.

\section{RESULTS}

There are figures of the surveys carried out following the guidelines corresponding to the research work will be shown.

In Fig. 2, it has the data of the study patients, where it can observe with respect to the level of depression in patients positive for coronavirus in North Lima, where 14 patients represent $60.9 \%$ of the total with a normal level of depression, 9 patients represent $39.1 \%$ of the total are slightly depressed.

Fig. 3 shows the data of the study patients in relation to gender, where it can see that 13 represents $65 \%$ of the total male sex who are with a normal level of depression, 7 represents $35 \%$ of the total sex males who are slightly depressed, 1 represents $33.3 \%$ of the total female sex who are with a normal level of depression and 2 represents $66.7 \%$ of the total female sex who are slightly depressed.

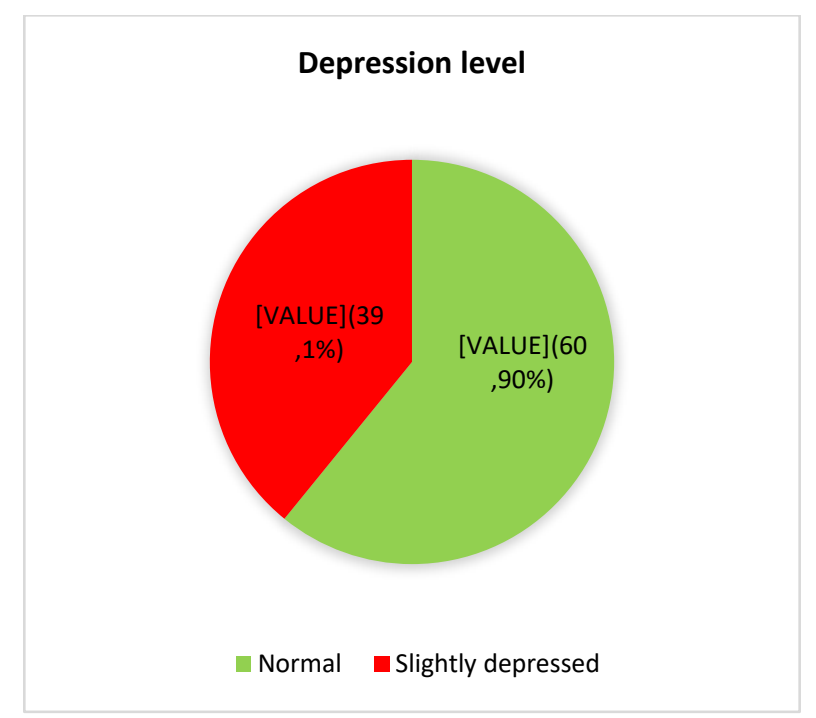

Fig. 2. Level of Depression in COVID-19 Positive Patients in the Puente Piedra District of North Lima, 2020. 


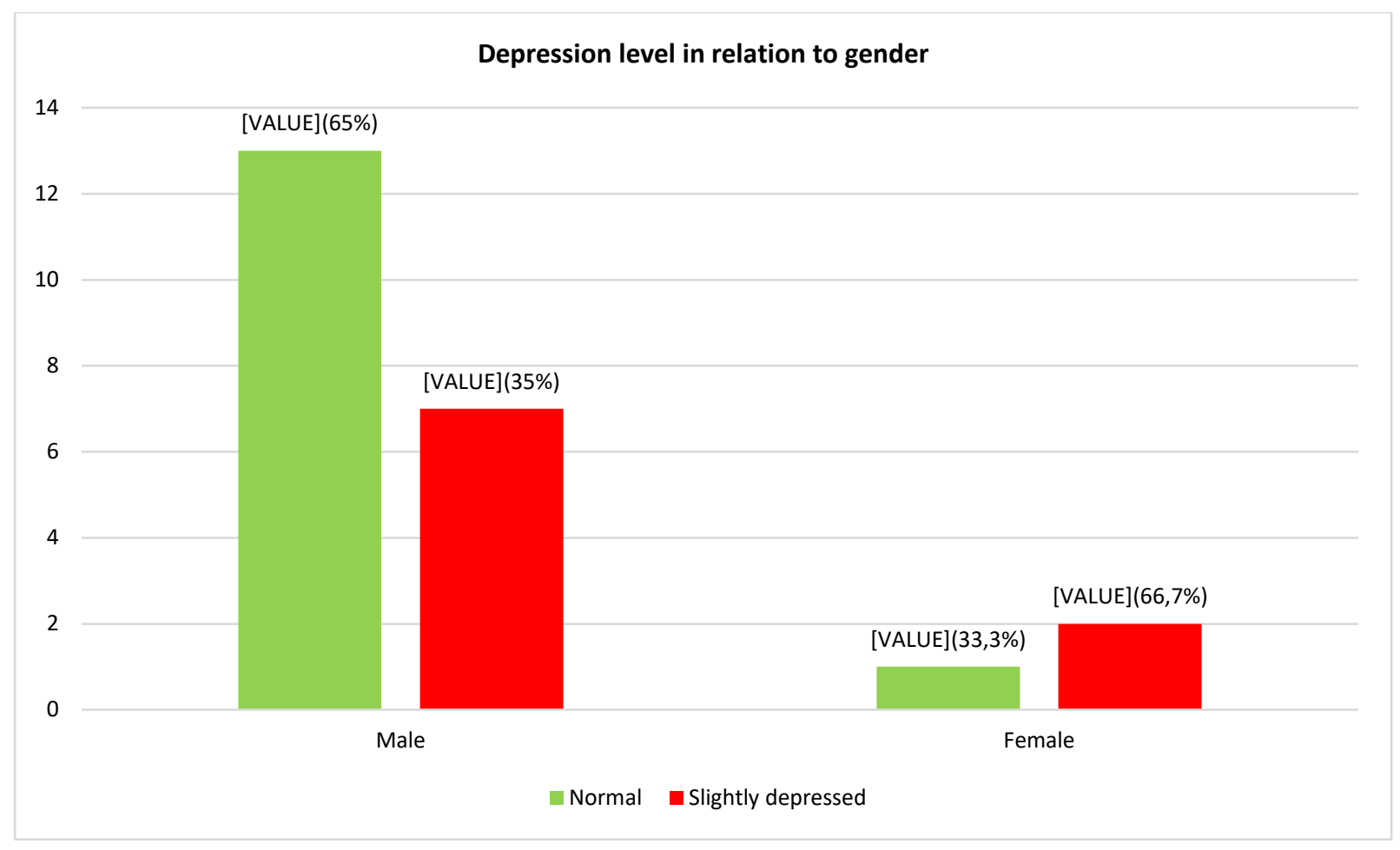

Fig. 3. Level of Depression in Relation to Gender in COVID-19 Positive Patients in the Puente Piedra District in North Lima, 2020.

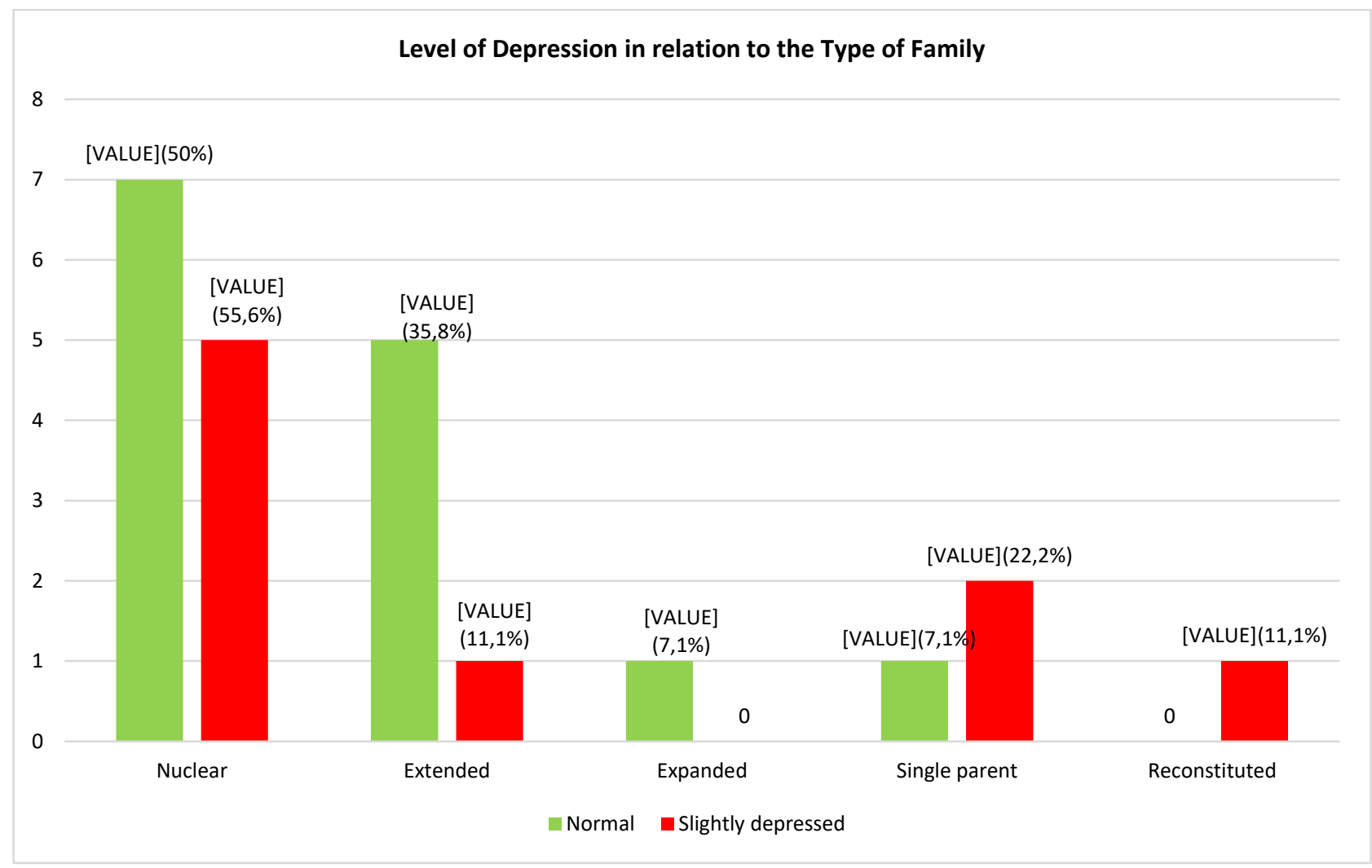

Fig. 4. Level of Depression in Relation to the Type of Family in Positive Patients for COVID-19 in the Puente Piedra District in North Lima, 2020. 
Fig. 4 shows the data of the study patients in relation to the type of family, where it can see that $7(50 \%)$ of the nuclear family type have a normal level of depression, 5 (55.6\%) of the type nuclear family are slightly depressed, $5(35.8 \%)$ of the extended family type have a normal level of depression, 1 $(11.1 \%)$ of the extended family type are slightly depressed, 1 $(7.1 \%)$ of the type expanded family have a normal level of depression, $1(7.1 \%)$ of the type of single parent have a normal level of depression, $2(22.2 \%)$ of the type of single parent are slightly depressed and 1 (11.1\%) of the reconstituted family type are slightly depressed.

These results are important since they will give data to know if the COVID-19 positive patient is depressed because of the disease.

\section{DISCUSSION}

In this research work, an approach is given to the mental health of the COVID-19 positive patient who is treated at home, although it is true because of the isolation due to the disease, the patient suffers a depressive state that affects themselves daily life and at the same time generates an impact on the family, causing a degree of psycho-emotional decline because of it.

In the results on the level of depression, it can be seen that the patients present a degree of depression due to COVID-19, this is because the disease has generated a substantial impact on the mental health of patients who tested positive for COVID-19 [18], although it is true some patients tend to show depressive symptoms because they feel distressed and worried about thinking that they can infect their families, therefore their psycho-emotional state tends to decrease and they do not face the situation properly. In the study by Choi E. et al. [6], they argue that patients who tested positive for COVID-19 had a deterioration in mental health and therefore had depression, this is because the patients felt overwhelmed by receiving information about COVID - 19 generating more anguish and concern in them, affecting them and altering the mental health of patients. Likewise Vindegaard N. and collaborator [15], argue that COVID-19 positive patients present a high index of depressive symptoms due to low psychological well-being and poor quality of sleep and being worried about their families increased symptoms regarding depression.

In the results on the level of depression in relation to sex, it was observed that in men there is evidence of a degree of depression due to COVID-19, this is due to the fact that men as head of the family, by testing positive for the disease, they have to think that they will not be able to work, in how to support their family, and also how to handle the situation due to isolation and quarantine, all this has generated in their mental health concern not only for themselves but for the rest of their family. Likewise, in the study by Ozamiz N. and collaborators [8], it was evidenced that women tended to manifest higher levels of depression than men, this is due to the fact that women have a high vulnerability with respect to health mentally, this is because stressors from COVID-19 make them more susceptible to depression [17], as their role as mother, wife, and caregiver coupled with pressure at home from isolation and quarantine has increased its stress therefore leads to depression. Similarly, Newby J. and collaborators [12], highlight that the mental health of the caregiver or parent who stays at home was associated with loneliness, the future and financial worries that were indications of having high levels of depression more frequently in women. Jia R. and collaborators [13], stated in their study that women were more associated with high levels of depression due to their mood, loneliness and concern about the COVID-19 pandemic. In the same way, Dai L . and collaborators [14], reported that women with relatives with COVID-19 had a high probability of presenting symptoms of depression due to family burden and psychological distress to care for their relatives.

In the results on the level of depression in relation to the type of family, it can be seen that the type of nuclear family has a degree of depression due to COVID-19, this is because the families had a negative impact at the time of knowing that a relative tested positive for COVID-19, although it is true that the family must emotionally support the patient but at the same time they must also seek emotional support with their other relatives because the effect on mental health exerted by COVID-19 towards families is alarming because they show signs of concern, anguish and despair when they know that a relative suffers from the disease [16], therefore, the union in the family is very important to be able to cope with these moments of isolation and quarantine due to COVID-19. Likewise, Orte C. and collaborators [11] refer that they maintain that family support during isolation due to COVID19 is very important in the family since this allows for a good life bond with other relatives and that the impact on mental health exerted by COVID-19 does not affect another member of the family.

\section{CONCLUSION}

In conclusion, brief psychological support should be given at home to patients who tested positive for COVID - 19 in which it will allow them to maintain their balanced health and be able to handle the situation properly.

In conclusion, intervention should be made on the psychological aspect according to the characteristics of each patient such as gender and age.

In conclusion, it is necessary to intervene in the psychological aspect to prevent and treat the decrease in depression in COVID-19 positive patients that it may create during and after the pandemic.

In conclusion, it is recommended to carry out continuous follow-ups by the nursing professional through home visits to observe the psychological aspect of the patient and provide emotional support in each visit that is made.

In a future research work, it is recommended to carry out more research at the national level, since it will allow researchers to go into more detail about the mental health of the patient during and after the COVID-19 pandemic.

The limitation in this research work is access to the homes of each patient, due to the fact that the relatives expressed mistrust at the time of conducting the surveys. 


\section{REFERENCES}

[1] Jakovljevic M, Bjedov S, Jaksic N, and Jakovljevic I, "Covid-19 pandemia and public and global mental health from the perspective of global health security. Psychiatria Danubina[revista en internet] 2020 [acceso 25 de agosto del 2020]; 31(1): 6-14."

[2] Wei $\mathrm{N}$ et al., "Efficacy of internet-based integrated intervention on depression and anxiety symptoms in patients with COVID-19. Journal of Zhejiang University: Science B[revista en internet] 2020 [acceso 25 de agosto del 2020]; 21(5): 400-404."

[3] Liu X et al., "Psychological status and behavior changes of the public during the COVID-19 epidemic in China. Infectious Diseases of Poverty[revista en internet] 2020 [acceso 25 de agosto del 2020]; 9(1): 1-11."

[4] Klomek A, "Suicide prevention during the COVID-19 outbreak. The Lancet Psychiatry[revista en internet] 2020 [acceso 25 de agosto del 2020]; 7(5): 390."

[5] Cullen W, Gulati G, and Kelly B, "Mental health in the COVID-19 pandemic. QJM : monthly journal of the Association of Physicians[revista en internet] 2020 [acceso 26 de agosto del 2020]; 113(5): 311-312."

[6] Choi E, Hui B, and Wan E, "Depression and anxiety in Hong Kong during covid-19. International Journal of Environmental Research and Public Health[revista en internet] 2020 [acceso 25 de agosto del 2020]; 17(10): 10."

[7] Lei L, Huang X, Zhang S, Yang J, Yang L, and Xu M, "Comparison of Prevalence and Associated Factors of Anxiety and Depression among People Affected by versus People Unaffected by Quarantine during the COVID-19 Epidemic in Southwestern China. Medical Science Monitor[revista en internet] 2020 [acceso 25 de agosto del 2020]."

[8] Ozamiz N, Dosil M, Picaza M, and Idoiaga N, "Niveles de estrés, ansiedad y depresión en la primera fase del brote del COVID-19 en una muestra recogida en el norte de España. Cadernos de Saude Publica[revista en internet] 2020 [acceso 25 de agosto del 2020]; 36(4): 1-10."

[9] Fernández C and Baptista P, Metodología de la Investigación. 6ta ed. México: Mc Graw-Hill/Interamericana; 2015.

[10] Zung W, "Escala de Autoevaluación para la Depresión de Zung.” pp. 12, 1965.

[11] Orte C, Ballester B, and Nevot L, "Apoyo Familiar ante el COVID - 19 en España. Universitat de les Illes Balears[revista en internet] 2020 [acceso 16 de setiembre del 2020]; 1-12."
[12] Newby J, O’Moore K, Tang S, Christensen H, and Faasse K, “Acute mental health responses during the COVID-19 pandemic in Australia. PLoS ONE[revista en internet] 2020 [acceso 28 de octubre del 2020]; 15(7):1-21.," doi: 10.1371/journal.pone.0236562.

[13] Jia R et al., "Mental health in the UK during the COVID-19 pandemic: cross-sectional analyses from a community cohort study. BMJ open[revista en internet] 2020 [acceso 28 de octubre del 2020]; 9(10): 40620.," doi: 10.1136/bmjopen-2020-040620.

[14] Dai L et al., "Anxiety and depressive symptoms among COVID-19 patients in Jianghan Fangcang Shelter Hospital in Wuhan, China. PLoS ONE[revista en internet] 2020 [acceso 28 de octubre del 2020]; 15(8):111.," doi: 10.1371/journal.pone.0238416.

[15] Vindegaard N and Benros M, "COVID-19 pandemic and mental health consequences: Systematic review of the current evidence. Brain, Behavior, and Immunity 2020; 89: 531-542.,". Available: https://www.ncbi.nlm.nih.gov/pmc/articles/PMC7260522/pdf/main.pdf.

[16] P. Herrera-Añazco and C. Toro-Huamanchumo, "Medical education during the COVID -19 pandemic: global initiatives for undergraduate, internship, and medical residency," Acta Med Peru, vol. 37, no. 2, p. 175, Apr. 2020, doi: 10.35663/amp.2020.372.999.

[17] M. Walton, E. Murray, and M. D. Christian, "Mental health care for medical staff and affiliated healthcare workers during the COVID-19 pandemic," Eur. Hear. J. Acute Cardiovasc. Care, vol. 9, no. 3, pp. 241247, Apr. 2020, doi: 10.1177/2048872620922795.

[18] WHO, "Mental health and COVID-19," World Health Organization, 2019. https://www.euro.who.int/en/health-topics/health-emergencies/ coronavirus-covid-19/technical-guidance/mental-health-and-covid-19 (accessed Aug. 03, 2020).

[19] N. W. S. Chew et al., "A multinational, multicentre study on the psychological outcomes and associated physical symptoms amongst healthcare workers during COVID-19 outbreak," Brain. Behav. Immun., vol. 88, p. 565, Apr. 2020, doi: 10.1016/j.bbi.2020.04.049.

[20] OPS/OMS, "Enfermedad por el Coronavirus (COVID-19)," Organización Panamericana de la Salud, Mar. 15, 2020. https://www. paho.org/es/tag/enfermedad-por-coronavirus-covid-19 (accessed Aug. 17, 2020).

[21] X. Xiao, X. Zhu, S. Fu, Y. Hu, X. Li, and J. Xiao, "Psychological impact of healthcare workers in China during COVID-19 pneumonia epidemic: A multi-center cross-sectional survey investigation," J. Affect. Disord., vol. 274, pp. 405-410, May 2020, doi: 10.1016/j.jad.2020.05.081. 